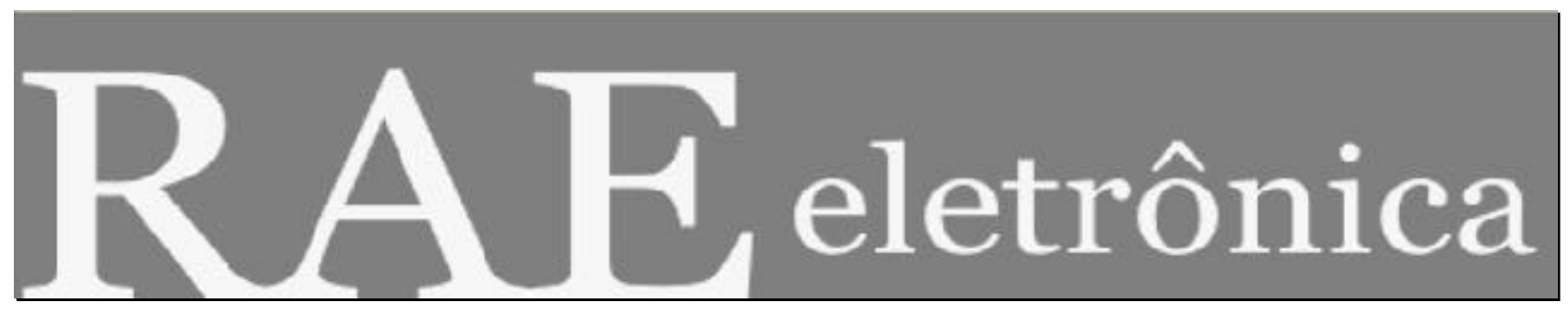

FÓRUM - A TEORIA INSTITUCIONAL EM UM CONTEXTO BRASILEIRO:

DINÂMICAS DE INOVAÇÃO E IMITAÇÃO

\title{
O INSTITUCIONALISMO E A ABORDAGEM DAS INTERAÇÕES ESTRATÉGICAS DA FIRMA
}

Por:

\section{Marcelo Bronzo \\ Luiz Honório}

RAE-eletrônica, v. 4, n. 1, Art. 5, jan./jul. 2005

http://www.rae.com.br/eletronica/index.cfm?FuseAction=Artigo\&ID=2095\&Secao=FOR.TE.INS\&Vol ume $=4 \&$ Numero $=1 \&$ Ano $=2005$

(C)Copyright, 2005, RAE-eletrônica. Todos os direitos, inclusive de tradução, são reservados. É permitido citar parte de artigos sem autorização prévia desde que seja identificada a fonte. A reprodução total de artigos é proibida. Os artigos só devem ser usados para uso pessoal e nãocomercial. Em caso de dúvidas, consulte a redação: raeredacao@fgvsp.br.

A RAE-eletrônica é a revista on-line da FGV-EAESP, totalmente aberta e criada com o objetivo de agilizar a veiculação de trabalhos inéditos. Lançada em janeiro de 2002, com perfil acadêmico, é dedicada a professores, pesquisadores e estudantes. Para mais informações consulte o site $\underline{\text { www.rae.com.br/eletronica. }}$

\section{RAE-eletrônica}

ISSN 1676-5648

C2005 Fundação Getulio Vargas - Escola de Administração de Empresas de São Paulo.

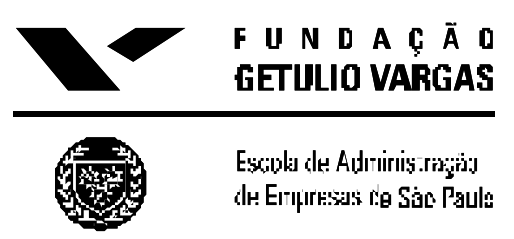


FÓRUM - A TEORIA INSTITUCIONAL EM UM CONTEXTO BRASILEIRO: DINÂMICAS DE INOVAÇÃO E IMITAÇÃO - O INSTITUCIONALISMO E A ABORDAGEM DAS INTERAÇÕES ESTRATÉGICAS DA FIRMA

Marcelo Bronzo - Luiz Honório

\section{RESUMO}

O artigo apresenta o desenvolvimento de uma perspectiva multidisciplinar para o estudo do comportamento das empresas e demais instituições econômicas no capitalismo contemporâneo. A partir de um extenso levantamento bibliográfico sobre o tema, este trabalho procura integrar contribuições oriundas de três abordagens teóricas fundamentais à temática do institucionalismo - a economia dos custos de transação, a perspectiva evolucionista e a abordagem das interações estratégicas da firma. Em conjunto, essas abordagens oferece $m$ contribuições relevantes para uma análise mais robusta sobre a importância das capacidades relacionais das firmas no contexto dos novos arranjos produtivos, em especial no contexto das redes organizacionais.

\section{PALAVRAS-CHAVE}

Cadeias produtivas, governança, redes organizacionais, teoria dos custos de transação, abordagem evolucionista.

\section{ABSTRACT}

This article presents the development of a multidisciplinary perspective for the study of the behaviour of companies and other economic institutions in contemporary capitalism. Based on an extensive survey of the literature on this topic, it seeks to integrate some of the contributions originating from three theoretical approaches fundamental to the theme of institutionalism - the transactions cost economics, the evolutionary perspective and the strategic interactions approach. Together, these perspectives offer significant contributions to a more robust analysis of the importance of companies' relational capacity in the context of new production arrangements, especially in the context of organisational networks.

\section{KEY WORDS}

Supply chains, governance, organizational networks, transaction cost theory, evolutionary perspective. 


\section{FÓRUM - A TEORIA INSTITUCIONAL EM UM CONTEXTO BRASILEIRO: DINÂMICAS DE INOVAÇÃO E IMITAÇÃO - O INSTITUCIONALISMO E A ABORDAGEM DAS INTERAÇÕES ESTRATÉGICAS DA FIRMA

INTRODUÇÃO

As forças teóricas que fundaram uma importante corrente do institucionalismo econômico podem ser remetidas às influências de Coase (1937) e, posteriormente, às bases conceituais do que se convencionou denominar como a economia dos custos de transação (transactions cost economics), essencialmente marcada pelos trabalhos de Williamson $(1975 ; 1985)$.

As premissas que sustentam o desenvolvimento da economia dos custos de transação são relativamente simples. O surgimento da firma deve-se à motivação de reduzir os custos de transação: a depender das incertezas ambientais e comportamentais dos agentes (neste último caso, a incerteza refere-se ao oportunismo, fundamentalmente) e da intensidade dos investimentos em ativos específicos envolvidos, os custos de transação podem ser tão significativos que a empresa poderá perceber vantagens em integrar verticalmente todas as operações e processos que, anteriormente, eram adquiridos através de transações com outras empresas no mercado (Williamson, 1985; Barney, 1999).

Apesar de robusta, a abordagem da economia dos custos de transação tem recebido críticas variadas. Entre estas, duas são recorrentes: a excessiva orientação para a análise individual tanto das transações quanto das firmas (sendo, portanto, baixo o seu potencial explicativo para a análise dos vínculos de relacionamentos em contextos mais amplos, como o de uma cadeia de suprimentos); o caráter estático das suas análises comparativas; o seu viés normativo; o foco primordialmente orientado para transações que envolvem ativos físicos, em detrimento dos ativos intangíveis, tais como as economias de aprendizagem, as capacidades dinâmicas e a reputação das firmas (Barney, 1999; Barney e Hansen, 1994; Nohria, 1992; Lorenzoni e Lipparini, 1999).

A análise dos vínculos interorganizacionais em um contexto mais amplo e o impacto das estruturas de governança sobre a gestão desses relacionamentos têm sido objeto de inúmeros estudos publicados na literatura especializada, sendo alguns trabalhos especialmente interessados na investigação da capacidade relacional das firmas em contextos de novos arranjos produtivos, como parece ser o caso das estruturas em rede (Kogut, 1991; Barney, 1999; Dyer e Ouchi, 1993; Lorenzoni e Lipparini, 1999; Cooke e Morgan, 1998; Nohria, 1992; Ebers, 1997).

É preciso reconhecer, primeiramente, que o estabelecimento de vínculo s por parte de uma organização apresenta motivações as mais variadas: serviços, produtos físicos, acesso a recursos financeiros, tecnologia, aprendizagem, desenvolvimento de competências, entre outros. As instituições afetam, fundamentalmente por sua presença e pela direção das suas decisões, a maneira através da qual os agentes econômicos irão procurar satisfazer racionalmente todos esses objetivos imediatos, a partir de interações estratégicas com outros agentes, sejam estes indivíduos, empresas, instituições governamentais, sindicatos patronais e de trabalhadores, escolas técnicas, câmaras de comércio, entidades certificadoras, entre outros.

O reconhecimento de que as instituições podem afetar diretamente a natureza e a direção das estruturas de relacionamento interorganizacional é uma premissa importante no desenvolvimento deste artigo, composto por três seções de argumentação. Na primeira seção, para efeito de melhor compreensão do problema da coordenação das atividades econômicas e dos recursos da firma, são apresentadas duas perspectivas: a coordenação das atividades econômicas como um processo de alocação de recursos e como um processo de criação de recursos. A primeira perspectiva está sedimentada no arcabouço teórico da economia dos custos de transação (Williamson, 1975; 1985), e, a segunda, nas abordagens 
FÓRUM - A TEORIA INSTITUCIONAL EM UM CONTEXTO BRASILEIRO: DINÂMICAS DE INOVAÇ̃̃O E

IMITAÇÃO - O INSTITUCIONALISMO E A ABORDAGEM DAS INTERAÇÕES ESTRATÉGICAS DA FIRMA Marcelo Bronzo - Luiz Honório

dos recursos da firma (RBV) e nas contribuições da teoria evolucionista. Na segunda seção, as abordagens da teoria dos custos de transação e da corrente evolucionista são integradas para possibilitar uma discussão mais ampla sobre as novas estruturas de relacionamento em rede, e sobre a importância dessas novas estruturas para as dinâmicas concorrenciais mais recentes, marcadas pelo fenômeno da desverticalização da produção e da inovação, e pela crescente e necessária especialização de funções no âmbito das cadeias produtivas. Na última seção do trabalho, defende-se a importância da abordagem das interações estratégicas da firma (Hall e Soskice, 2001) para os estudos institucionalistas e para as pesquisas nos campos da economia industrial e da teoria das organizações. Por fim, são apresentadas as conclusões do trabalho.

\section{A COORDENAÇÃO DAS ATIVIDADES ECONÔMICAS EM UMA PERSPECTIVA DE ALOCAÇÃO E DE CRIAÇÃO DE RECURSOS}

\section{A coordenação da atividade econômica como um processo de alocação de recursos}

Quais são as atividades e os respectivos processos de negócio que devem estar sob o controle interno das firmas e quais devem ser organizados fazendo-se uso extensivo de práticas de terceirização?

Muitos estudos desenvolvidos no campo da economia dos custos de transação estão interessados exatamente em determinar quais condições as empresas devem gerenciar internamente certas operações e em quais circunstâncias tais operações devem ser desintegradas verticalmente, por meio das estratégias de terceirização.

Para a economia dos custos de transação, a definição de tais condições envolve a análise quanto à presença de ativos específicos nas relações contratuais (transaction-specific investments). Além da especificidade de ativos, são também considerados os pressupostos comportamentais dos agentes como a racionalidade limitada e o oportunismo - e fatores ambientais, como a complexidade dos cenários e o número de agentes econômicos em um determinado contexto institucional (Williamson, 1975).

Também a questão dos contratos é crítica para a economia dos custos de transação. Isso porque a figura jurídica dos contratos objetiva, em última instância, facilitar o processo de trocas, e para cada sistema contratual podem ser desenvolvidas formas particulares de governança. Com base nessa premissa, o modelo "williamsoniano" (Williamson, 1975 e 1985) define (i) o enquadramento das formas clássicas de contrato e de governança com o mercado; (ii) a presença de formas híbridas e de estruturas de governança trilateral; (iii) o enquadramento das formas relacionais de governança bilateral e de governança unificada.

Pela orientação legal clássica, a identidade dos agentes no processo de contratação é uma condição restrita ou irrelevante. Os acordos são fundados em regras legais, documentos formais e em contrapartidas que podem ser exaustivamente prescritas. Os contratos clássicos orientam se para tipos recorrentes e/ou ocasionais de transação de componentes, serviços ou produtos padronizados. Se não há a necessidade de investimentos em ativos específicos, o objeto da transação não for considerado 
FÓRUM - A TEORIA INSTITUCIONAL EM UM CONTEXTO BRASILEIRO: DINÂMICAS DE INOVAÇ̃̃O E

IMITAÇÃO - O INSTITUCIONALISMO E A ABORDAGEM DAS INTERAÇÕES ESTRATÉGICAS DA FIRMA

Marcelo Bronzo - Luiz Honório

estratégico por algum parâmetro específico ou se houver muitas alternativas de fornecimento, o mercado atuará de forma eficiente no controle de possíveis comportamentos oportunistas por parte dos agentes econômicos, sendo facilitada a qualquer uma das partes a decisão em continuar ou não o relacionamento.

O contrato do tipo neoclássico avança em relação ao tipo clássico ao reconhecer os impactos da racionalidade limitada dos agentes e a natureza incompleta dos acordos contratuais. Trata-se do contrato típico de transações ocasionais que envolvem níveis medianos ou intensos de investimentos em ativos específicos. Essa estrutura de governança - e talvez aqui se possa pensar em termos de uma forma institucional intermediária ou híbrida - tem na arbitragem e nas reconhecidas "terceiras partes" um caminho para a resolução de disputas e para a avaliação da performance dos agentes. Distancia-se assim da orientação restritiva das cortes judiciais ou das decisões litigiosas, que tendem geralmente a não prezar, antes de tudo, a perspectiva de continuidade dos contratos.

Já os contratos relacionais identificam-se com formas quase administrativas que viabilizam a gestão das transações. Há o interesse das partes em construir e manter uma estrutura especializada de governança, necessária às transações recorrentes de produtos não-standardizados e demandantes de investimentos específicos, ou de conteúdo idiossincrático. Nesse caso, a opção da compra pelo mercado pode ser altamente duvidosa e arriscada, sobretudo em condição de incertezas, de especificidade de ativos e de transações recorrentes ao longo do tempo. Um detalhe importante distingue os contratos relacionais: existem as formas bilaterais e as formas unificadas de governança. Nas formas bilaterais, há autonomia das partes e menor especialização de ativos. Na forma unificada, as transações são removidas do mercado e são totalmente internalizadas, como acontece nos processos radicais de verticalização. Os custos de transação são substituídos por custos administrativos, e esse procedimento confere à empresa verticalizada um espaço mais amplo de manobras em relação a várias questões, como política de preços, decisões relativas à quantidade e à frequiência da produção, objetivos de redução drástica dos custos de produção, entre outras.

Em resumo, a economia dos custos de transação define as estruturas de governança como mecanismos através dos quais as empresas gerenciam transações, sendo possível contextualizar essas estruturas em três grandes categorias: de mercado, intermediárias e hierárquicas. A definição dos mecanismos relativos a essas estruturas afeta diretamente os limites de eficiência das firmas e pode representar soluções com custos e potenciais diferenciados para a mitigação do oportunismo nas transações econômicas.

Quanto mais sofisticada a estrutura de governança, tanto maior o seu custo, porém tanto maior a sua efetividade na contenção do oportunismo criado pelo alto investimento em ativos específicos na transação. A necessidade de pesados investimentos em ativos específicos e a elevada incerteza ambiental e comportamental sugerem a estrutura hierárquica como melhor opção. Níveis moderados de investimentos em ativos específicos sugerem a utilização de estruturas do tipo intermediária, capazes de conter o oportunismo sem os custos extras da estrutura hierárquica. Por fim, para transações caracterizadas pela inexistência ou por baixos investimentos em ativos específicos - e, portanto, para situações para as quais o comportamento oportunista não é esperado - as estruturas de governança pelo mercado são as mais indicadas, segundo Barney (1999), pelo baixo custo de tal solução.

\section{A coordenação da atividade econômica como um processo de criação de recursos}


FÓRUM - A TEORIA INSTITUCIONAL EM UM CONTEXTO BRASILEIRO: DINÂMICAS DE INOVAÇÃO E IMITAÇÃO - O INSTITUCIONALISMO E A ABORDAGEM DAS INTERAÇÕES ESTRATÉGICAS DA FIRMA Marcelo Bronzo - Luiz Honório

Aos olhos dos evolucionistas, a economia dos custos de transação representa um conjunto de teorizações importante nos estudos da firma e da estratégia organizacional. Mas lhe falta ainda, entre outros pontos, ampliar o enfoque para além do aspecto contratual das transações. Essa superação implica uma análise do que fazem as firmas nos seus limites internos e de como se dão seus processos de aprendizagem, de formação e de utilização de competências complementares - tecnológicas e organizacionais - em uma perspectiva temporal e de longo prazo (Freeman e Boeker, 1984; Nelson e Winter, 1982; Teece, Pisano e Shuen, 1997; Sobrero, 1996).

Assim, a especificidade de ativos, tão importante para a teoria dos custos de transação, divide o foco de atenção com as competências da firma, cujas implicações sobre a organização econômica são igualmente importantes. A idéia aqui é a de que não há algo mais idiossincrático a uma organização do que o conjunto de suas competências, tanto internas quanto relacionais (Nelson e Winter, 1982). Assim, embora seja relevante compreender de que forma as organizações continuamente criam e recriam competências e vantagens competitivas a partir do controle de determinados recursos e ativos no interior dos seus limites de eficiência, é também importante considerar que a competitividade mostrase quase sempre dependente da forma como as organizações gerenciam, com o tempo e com suas experiências, as suas estruturas de relacionamento interorganizacional, com repercussões nos custos de transação e nas economias de aprendizagem.

Isso não quer dizer que a posse de ativos e de recursos tangíveis, bem como a presença de capacidades internas, não importem à competitividade da empresa. Simplesmente quer-se ressaltar que essa não parece ser a dimensão mais importante para sustentar a competitividade estrutural e a rentabilidade da empresa no futuro. Para uma discussão específica sobre o problema das competências organizacionais e da gestão dos vínculos de relacionamento entre as empresas, é importante recuperar uma de suas influências mais marcantes, presente nos primeiros estudos da abordagem evolucionista.

A abordagem evolucionista de corte neo-schumpeteriano introduziu o aspecto dinâmico necessário no debate sobre a firma. Deseja-se ressaltar com isso que algumas capacidades da firma, como a aprendizagem e o relacionamento com outras empresas, assumem um papel central na manutenção da vantagem competitiva em longo prazo (Teece, Pisano e Shuen, 1997). Aqui, os processos que determinam a vantagem competitiva de uma empresa são os mesmos que lhe irão permitir a sobrevivência ao longo do tempo: sua capacidade de criar e recriar continuamente novas competências, tanto internas como a partir do contato com outras organizações.

Para a abordagem evolucionista, as empresas possuem um conjunto de capacidades e de competências que, ao longo do tempo, modificam-se, tanto em razão de seus próprios esforços na solução de problemas quanto em função de eventos aleatórios ou inesperados que impulsionam o seu processo de mudança. Assim, a teoria das capacidades dinâmicas da firma, como proposta em Teece, Pisano \& Shuen (1997), integra-se à abordagem da teoria dos custos de transação, estabelecendo suas raízes em diferentes referências, como as de Schumpeter (1911), Penrose (1959), Williamson (1975), Nelson e Winter (1982), Prahalad e Hamel (1990).

As capacidades da firma e sua habilidade (dinâmica) em recriar competências, a fìm de responder às mudanças do ambiente, implicam que a experiência e a aprendizagem podem ser fontes de vantagens competitivas, não obstante os aspectos de rigidez dos investimentos em ativos específicos e de outros elementos que conformam a trajetória de evolução da empresa (Lipparini, 1998). 
FÓRUM - A TEORIA INSTITUCIONAL EM UM CONTEXTO BRASILEIRO: DINÂMICAS DE INOVAÇ̃̃O E

IMITAÇÃO - O INSTITUCIONALISMO E A ABORDAGEM DAS INTERAÇÕES ESTRATÉGICAS DA FIRMA

Marcelo Bronzo - Luiz Honório

Útil à compreensão da idéia de capacidades dinâmicas é o entendimento do conceito - hoje bastante difundido - das competências centrais da firma. Esse conceito entrou na terminologia corrente da administração graças a Prahalad e Hamel (1990), que o utilizaram para indicar o papel estratégico da gerência em identificar, cultivar e explorar as competências centrais que definem a permanência das empresas no jogo competitivo. Prahalad e Hamel (1990) sugerem que, em curto prazo, a competitividade de uma empresa deriva de atributos de preço e performance de produtos já disponíveis nos mercados. Porém, dada a convergência de parâmetros dos custos de produção e da qualidade na maior parte das empresas, é legítimo indagar se esses atributos, embora essenciais, são capaze s, em médio e longo prazos, de sustentar uma vantagem competitiva diante dos ataques da concorrência. Em parte por esse motivo, entende-se que o problema da competitividade das empresas deve sempre ser visto em contextos de longo prazo. A competitividade de uma empresa depende da sua habilidade em construir mais rápido, antes e a um custo menor que seus concorrentes um conjunto de competências que viabilizem a disponibilidade de novos produtos e de novos processos.

Essa habilidade em alcançar novas formas de vantagem competitiva é entendida, como já visto, como uma capacidade dinâmica. É "capacidade" porque enfatiza a gestão empresarial no sentido de adaptar, integrar e reconfigurar habilidades, recursos e competências frente às novas exigências do mercado. E é "dinâmica" porque significa uma renovação contínua das competências organizacionais, à medida que mudam as características do ambiente de negócios. A noção de que a vantagem competitiva requer a exploração dinâmica e simultânea de capacidades internas e de recursos externos complementares é uma importante faceta do desenvolvimento recente do conceito da estratégia corporativa, e também um resultado a ser alcançado pelas novas estruturas organizacionais em redes.

\section{ARQUITETURAS ORGANIZACIONAIS EM REDE E RELACIONAMENTO ENTRE EMPRESAS}

A arquitetura em rede exemplifica um traço fundamental do comportamento corporativo recente: ao mobilizar capacidades e recursos para operar em um ambiente concorrencial profundamente redesenhado, as empresas estariam buscando paralelamente ativar e manter canais de relacionamento mais eficazes com outras empresas do seu campo organizacional, com a finalidade de assegurarem a sua própria sobrevivência ou incrementar a sua competitividade (Di Maggio e Powell, 1983; Nohria, 1992; Ring, 1997; Porter, 1998).

O nível e o tipo de confiança nas estruturas de relacionamento entre as empresas são elementos de análise fundamentais, sobretudo se um dos objetivos for observar a capacidade associativa das organizações em rede. Nesse sentido, a distinção entre formas frágeis e menos frágeis de confiança entre os agentes revela a natureza do relacionamento entre as firmas, embora ainda existam obstáculos de ordem metodológica e empírica a uma investigação desse tipo. As formas frágeis de confiança, segundo terminologia proposta por Ring (1997), são suficientes para viabilizar certos tipos de transação, mas de forma limitada. Nesse caso, a confiança é meramente instrumental, cumprindo apenas o papel de simplificação das relações econômicas. Geralmente acompanhada por mecanismos mais formalizados de salvaguardas, uma base precária de confiança associa-se ao arquétipo das formas e relações puras do mercado. Porém, uma maior expectativa entre os atores permite um nível de 
FÓRUM - A TEORIA INSTITUCIONAL EM UM CONTEXTO BRASILEIRO: DINÂMICAS DE INOVAÇ̃̃O E

IMITAÇÃO - O INSTITUCIONALISMO E A ABORDAGEM DAS INTERAÇÕES ESTRATÉGICAS DA FIRMA Marcelo Bronzo - Luiz Honório

confiança também ampliado, podendo impulsionar os agentes à edificação e ao desenvolvimento de estruturas de governança mais complexas e, em muitos casos, menos formalizadas (Ring, 1997).

Manobras competitivas de crescimento a partir da utilização estratégica de recursos externos complementares, como ocorre caracteristicamente nas estruturas em rede, implicam um novo patamar para a coordenação e o controle da cadeia logística e produtiva, e necessariamente requerem, como já dito, um tipo menos frágil de confiança por parte dos atores. Mas coordenação e controle representam funções que nem todas as empresas estão aptas a executar, uma vez que são necessários atributos, capacidades e competências particulares. Esses elementos - capacidades, competências, atributos dependem quase sempre da posição que a empresa ocupa no interior da rede, de sua história, de sua solidez financeira e de seu poder contratual em relação às outras organizações com as quais se relaciona em fases do ciclo produtivo. Mais importante que isso: a distribuição dessas capacidades e atributos no interior da rede é capaz de definir também o nível de assimetrias e de dependência entre os agentes. Essa questão merece ser aprofundada, diante dos efeitos que provoca no âmbito dos processos inovativos e da coordenação de recursos e competências entre empresas de uma mesma rede.

As organizações dependem do ambiente para conseguir os recursos essenciais à execução das suas atividades. Porém, as empresas não chegam a explorar esse ambiente de forma exclusiva, pela simples razão de que outras firmas podem também controlar os recursos de que necessita, tornando a troca um fenômeno fundamental para garantir sua sobrevivência (Barley, Freeman e Hybels, 1992). Diante dessa necessidade, intrínseca à própria atividade econômica, e a depender da forma como estão distribuídos os atributos e as competências entre os atores, diferentes níveis de dependência caracterizarão os elos possíveis entre as empresas (Dubois e Hakansson,1997). Tal interdependência de recursos pode ser mais ou menos forte, e os objetivos para sedimentar vínculos com outros agentes podem ser os mais variados, como exposto na primeira parte do trabalho: informação, suprimentos, serviços, acesso a recursos financeiros, tecnologia, aprendizagem, desenvolvimento de novas competências, entre outros.

As empresas que entram em um circuito relacional e encontram-se inseridas em uma estrutura em rede, sejam elas pequenas, médias ou grandes empresas, tenderão a se especializar em atividades para as quais suas capacidades e competências ofereçam alguma vantagem comparativa diante de seus concorrentes diretos ou potenciais. A favor dessa perspectiva há a tese, defendida por certos autores (Penrose, 1959; Richardson, 1996; Prahalad e Hamel, 1990), de que as organizações crescem influenciadas por seu conjunto de capacidades e habilidades, que podem ser expandidas, alteradas ou descartadas ao longo do tempo, construindo assim uma trajetória de desenvolvimento e uma estratégia de inovação particulares para essas organizações.

\section{Aprendizagem e coordenação do processo inovativo nas arquiteturas em rede}

No caso das estruturas em rede, além da redução dos custos de produção e de transação são impulsionadas também economias relativas à gestão da informação, ao seu uso e à aprendizagem. Essas razões são mais que suficientes para se aprofundar o estudo das estruturas em rede.

Para as empresas participantes de uma rede, um maior fluxo informacional significa a identificação clara de quem se responsabiliza por que coisa no interior da cadeia de valor, e pode vir a representar, sobretudo nos processos inovativos, fonte importante de vantagem competitiva (Sobrero, 1996; Lipparini, 1998). Esse potencial ganho de competitividade deriva da capacidade demonstrada pelos agentes de reconhecer, mobilizar e utilizar, de forma eficiente, competências quase sempre 
FÓRUM - A TEORIA INSTITUCIONAL EM UM CONTEXTO BRASILEIRO: DINÂMICAS DE INOVAÇÃO E

IMITAÇÃO - O INSTITUCIONALISMO E A ABORDAGEM DAS INTERAÇÕES ESTRATÉGICAS DA FIRMA

Marcelo Bronzo - Luiz Honório

sedimentadas no nível sistêmico da arquitetura em rede. E há motivos também para se crer que tal competência interorganizacional talvez se mostre mais relevante à competitividade das empresas do que o tamanho ou a capacidade produtiva das plantas industriais.

No que tange aos processos e às economias de aprendizagem no interior das formas em rede, a estratégia empresarial deve estar orientada à criação de valor e ao aumento da capacidade relacional da empresa, posto que uma maior habilidade das organizações em identificar e gerenciar suas estruturas de relacionamento implica também uma melhor gestão dos fluxos informativos e dos recursos no interior da cadeia produtiva. Portanto, quanto maior a habilidade na gestão dos relacionamentos por parte da empresa, mais consistente tende a ser a sua capacidade associativa, isto é, de absorver diferentes contribuições externas. A aprendizagem, no contexto de redes, está diretamente associada ao êxito da firma em internalizar e explorar eficientemente um conhecimento ou uma contribuição externa útil. Aqui as questões ligadas à localização geográfica podem ganhar enorme importância, por diferentes razões.

A região - entendida como a construção de uma ordem social, cultural e política particulares aparecerá sempre caracterizada por um certo nível de regulação microinstitucional, que facilita ou dificulta a emulação de comportamentos inovativos e capacidades associativas por parte das empresas. Por um lado, tem-se a face reguladora da região, que influencia a ação e a consciência coletiva dos atores por meio de suas instituições. Por outro, a região sofre as influências não somente do próprio comportamento das firmas, mas também (e em grande medida) de parâmetros nacionais e restrições internacionais.

O conceito de sistemas regionais de inovação faz referência à atuação de empresas, situadas parcial ou totalmente em uma mesma base local, que envidam esforços complementares para desenvolver e sustentar a inovação em áreas geográficas específicas. Laboratórios de pesquisa, agências de serviços, associações patronais, sindicatos de trabalhadores, universidades e centros de pesquisa básica ou aplicada, entre outros, podem facilitar a construção de clusters de empresas, nos quais a regionalização dos projetos inovativos e o favorecimento a economias associativas contribuem para a maximização do nível de eficiência e de competitividade da rede, das empresas e da região.

Igualmente relevante para a discussão dos processos inovativos em bases locais é o debate, hoje maduro, sobre a especialização flexível, fazendo-se referência também à dimensão espacial (Piore e Sabel, 1984; Piore, 1992; Perrow, 1992). Ao comentar as repercussões e as críticas sofridas a partir da publicação de um de seus trabalhos internacionalmente mais reconhecidos, Piore (1992) afirmou que, em momento algum, teria sido por ele proposta a aproximação do conceito de especialização flexível com uma trajetória tecnológica distinta - no caso, a microeletrônica e a tecnologia da informação. Ao contrário, as páginas do célebre "The second industrial divide" (Piore e Sabel, 1984) esclarecem uma argumentação do autor no sentido de que as formas institucionais, associadas ao avanço tecnológico e organizacional, evoluíram a partir de certas experiências produtivas em regiões do mundo. O que Piore e Sabel (1984) fizeram, portanto, foi associar a especialização flexível a uma terceira estrutura institucional, alternativa às formas da hierarquia e do mercado. Faz-se referência, assim, à transposição de um certo modelo de desenvolvimento industrial - baseado nas grandes corporações e na produção em massa de produtos standardizados - em direção a um modelo caracterizado por novos tipos de comunidades industriais, em que pequenas e médias empresas cumprem um papel fundamental na competitividade do sistema. 
FÓRUM - A TEORIA INSTITUCIONAL EM UM CONTEXTO BRASILEIRO: DINÂMICAS DE INOVAÇÃO E

IMITAÇÃO - O INSTITUCIONALISMO E A ABORDAGEM DAS INTERAÇÕES ESTRATÉGICAS DA FIRMA

Marcelo Bronzo - Luiz Honório

A competitividade da rede e a sustentação de vantagens ao longo do tempo dependem, então, de projetos de mais longa maturação, sobretudo porque é necessário criar uma nova estrutura de incentivos e de transferência de competências para todo o sistema, isto é, para pequenas, médias e grandes empresas.

\section{A ABORDAGEM DAS INTERAÇÕES ESTRATÉGICAS DA FIRMA}

Pressupõe-se que as decisões de curto e longo prazos tomadas pelas firmas estejam diretamente associadas à infra-estrutura institucional que contorna e suporta as dinâmicas de relacionamento entre os agentes econômicos em um mesmo campo interorganizacional, aos aspectos históricos e culturais de uma região ou população de organizações, bem como à capacidade relacional da firma ao longo do tempo. Esse é o contexto que a abordagem das interações estratégicas de Hall e Soskice (2001) procura analisar.

A estrutura institucional de uma determinada realidade econômica fornece às firmas certas vantagens para se empenharem em tipos específicos de atividades. Assim considerado, o apoio institucional recebido pode explicar as razões pelas quais certas organizações desempenham algumas atividades mais eficientemente do que outras. Embasados pela literatura sobre o tema, é argumentado que as nações freqüentemente prosperam não por se tornarem mais similares, mas por construírem suas diferenças institucionais. Esse é o conceito de vantagem institucional comparativa defendido por Hall e Soskice (2001).

Todavia, esses autores observam que as instituições não são capazes, unicamente, de sustentar esses tipos específicos de atividades. Também é requerido um conjunto comum de conhecimentos e de crenças que reflita o entendimento que cada empresa possui sobre seu papel e sobre seus interesses nas atividades de interação, como também alguma confiança nas instituições que apóiam tais atividades.

Explicar como as instituições afetam os novos formatos de organização, principalmente no que se refere à capacidade relacional das firmas, representa o cerne da abordagem de Hall e Soskice (2001). Por essa abordagem, a arena econômica é vista como um terreno povoado por múltiplos atores que buscam satisfazer racionalmente seus interesses interagindo estrategicamente com outros agentes, tais como indivíduos, empresas, instituições governamentais, sindicatos patronais e de trabalhadores, escolas técnicas, câmaras de comércio, entidades certificadoras, entre outros.

Com exceção de alguns importantes trabalhos que procuraram estabelecer modelos para a compreensão do relacionamento interorganizacional (Hollingsworth e Boyer, 1997; Crouch e Streek, 1997; Whitley, 1999), muitos modelos deixam escapar ou tratam incompletamente o modo como as instituições condicionam o comportamento estratégico interativo entre os agentes econômicos. A abordagem de Hall e Soskice (2001) focaliza os mesmos elementos tratados pelos modelos convencionais, mas representa um novo combustível ao "reforçar" uma ponte entre estudos administrativos e microeconômicos, que freqüentemente não são vistos como complementares para explicar os fenômenos relativos ao comportamento das firmas. 
FÓRUM - A TEORIA INSTITUCIONAL EM UM CONTEXTO BRASILEIRO: DINÂMICAS DE INOVAÇÃO E

IMITAÇÃO - O INSTITUCIONALISMO E A ABORDAGEM DAS INTERAÇÕES ESTRATÉGICAS DA FIRMA

Marcelo Bronzo - Luiz Honório

Tal abordagem diverge da corrente principal que normalmente norteia as visões sobre os novos formatos de organização. Embora ela considere o modelo dicotômico de hierarquias e mercados de Williamson (1975), também determina que pode haver variação importante entre as características da estrutura corporativa (ou hierarquia) em diferentes tipos de economia e a presença de problemas de coordenação até mesmo dentro das estruturas hierárquicas. Mercados e hierarquias, portanto, não são as únicas formas que as firmas utilizam para enfrentar seus desafios. Existem muitas firmas, em economias coordenadas de mercado, que desenvolvem relacionamentos cooperativos através de dispositivos institucionais que apóiam compromissos de confiança entre os parceiros (Hall e Soskice, 2001).

Os seguintes elementos da abordagem de Hall e Soskice (2001) interessam de perto ao objetivo deste artigo: (i) uma visão relacional da firma; (ii) os tipos de economias de mercado; (iii) o papel das instituições e das organizações; e (iv) o papel da cultura, das regras informais e da história. A seguir, são apresentadas algumas breves referências sobre cada um desses pontos.

\section{Uma visão relacional da firma}

As firmas, em uma perspectiva relacional, são vistas como agentes econômicos que buscam desenvolver e explorar competências centrais ou capacidades dinâmicas para o desenvolvimento, a produção e a distribuição de bens e serviços rentáveis. A qualidade relacional da firma depende da sua habilidade de coordenar efetivamente os relacionamentos que estabelece tanto internamente, com os empregados, quanto externamente, com atores tais como fornecedores, clientes, colaboradores, acionistas, sindicatos, associações comerciais e governos.

Cinco esferas de investigação são sugeridas por Hall e Soskice (2001) para que as firmas desenvolvam relacionamentos para solucionar problemas de coordenação em função de suas competências centrais.

A primeira esfera diz respeito às "relações industriais", que se referem ao modo com que as firmas coordenam negociações salariais e de condições de trabalho com seus trabalhadores e com organizações que representam a mão-de-obra e outros empregadores. A esfera do "treinamento e da educação vocacional" relaciona-se à maneira com que as firmas criam condições para o desenvolvimento de habilidades da sua força de trabalho, bem como da capacidade de os empregados decidirem o quanto deve ser investido no desenvolvimento dessas habilidades. Uma terceira esfera trata de questões sobre "governança corporativa", e a orientação da firma volta-se para a maneira como ela coordena esforços para acessar recursos financeiros e buscar investidores que assegurem retornos para seus investimentos. A quarta esfera diz respeito às "felações interfirmas", principalmente no tocante aos relacionamentos que a firma estabelece com fornecedores e clientes para manter demanda estável para os produtos, suprimentos apropriados de inputs e acesso à tecnologia (padronização, transferência e arranjos colaborativos de P\&D). Finalmente, "relacionamento com os empregados" configura-se como a quinta esfera e dela se espera que a organização sja capaz de assegurar que empregados tenham as competências necessárias para cooperarem com outros empregados e para com a empresa, visando o alcance dos objetivos empresariais.

\section{Economias liberais e coordenadas de mercado}


FÓRUM - A TEORIA INSTITUCIONAL EM UM CONTEXTO BRASILEIRO: DINÂMICAS DE INOVAÇÃO E

IMITAÇÃO - O INSTITUCIONALISMO E A ABORDAGEM DAS INTERAÇÕES ESTRATÉGICAS DA FIRMA

Marcelo Bronzo - Luiz Honório

As economias políticas podem ser comparadas entre si quanto à maneira pela qual as firmas solucionam seus problemas de coordenação, por meio das cinco esferas anteriormente descritas. Essas economias podem ser classificadas em dois tipos ideais, economias liberais e economias coordenadas de mercado.

Em economias liberais de mercado, as firmas coordenam suas atividades por meios de hierarquias e arranjos competitivos de mercado. Tomando como referência o trabalho de Williamson (1975), Hall e Soskice (2001) reiteram que os relacionamentos de mercado nesse tipo de economia são caracterizados por transações de bens e serviços do tipo arm's length, em um contexto de competição e contratação formal. Portanto, os atores econômicos ajustam seus interesses de suprimento e demanda de bens e serviços em relação às variações de preço geradas pelo mercado.

Em economias coordenadas de mercado, as firmas dependem mais fortemente de relacionamentos de não-mercado para coordenar esforços com outros atores na construção de competências centrais. Modos de coordenação de não-mercado requerem relacionamento mais extensivo ou de contratação incompleta, monitoração da rede por intermédio de trocas de informações privadas, maior confiança na colaboração em oposição à competição e relacionamentos mais efetivos para construir as competências centrais. Assim, ao contrário das economias liberais de mercado, onde os resultados da firma são equilibrados em função das condições competitivas de demanda e suprimento do mercado, as economias coordenadas e seus resultados se equilibram mais freqüentemente em função da interação estratégica entre firmas e outros atores (Hall e Soskice, 2001).

Em resumo, embora muitas das nações desenvolvidas possam ser classificadas como economias coordenadas ou liberais de mercado, o ponto essencial é analisar diferentes tipos de coordenação de atividades e o apoio institucional correspondente. Mesmo dentro da classificação duopolista aqui colocada, variações significativas podem ser encontradas. As diferenciações residem em mecanismos de mercado versus de não-mercado para a coordenação de atividades econômicas. Quaisquer que sejam esses mecanismos, eles servem como referência para se compreender como a firma coordena esforços de relacionamento interno e externo.

Uma visão relacional da firma e os tipos de economia de mercado foram os elementos básicos da abordagem das interações estratégicas discutidos até o presente momento. Além deles, o papel das instituições, organizações, regras informais, cultura e história configuram-se em outros elementos importantes da abordagem, uma vez que tais estruturas apóiam os esforços que as firmas mobilizam para solucionar problemas de coordenação.

\section{O papel das instituições e organizações}

Partindo da literatura existente sobre este tema, Hall e Soskice (2001) definem instituições como um conjunto de regras, formais e informais, seguidas pelos atores seja por razões normativas, cognitivas ou materiais. As organizações são consideradas, pelos mesmos autores, como entidades estáveis compostas por membros formalmente organizados, cujas regras também contribuem para as instituições de economia capitalista. 
FÓRUM - A TEORIA INSTITUCIONAL EM UM CONTEXTO BRASILEIRO: DINÂMICAS DE INOVAÇÃO E IMITAÇÃO - O INSTITUCIONALISMO E A ABORDAGEM DAS INTERAÇÕES ESTRATÉGICAS DA FIRMA Marcelo Bronzo - Luiz Honório

Todavia, tanto instituições quanto organizações fornecem uma estrutura para a interação humana. As instituições, juntamente com o padrão de limitações da teoria econômica, determinam as oportunidades em uma sociedade. As organizações são criadas para tirar vantagem dessas oportunidades, e, como as organizações evoluem, elas alteram as instituições. O caminho resultante da mudança institucional é moldado pelo (i) relacionamento de simbiose encerrado entre instituições e organizações, o qual tem evoluído como uma consequiência da estrutura de incentivos institucionais, e (ii) pelo processo de feedback por meio do qual os seres humanos percebem e reagem a determinadas oportunidades (North, 1990).

Os mercados são instituições que apóiam relacionamentos marcados por relações do tipo arm's length e por altos níveis de competição. Toda economia capitalista também contém as hierarquias que as firmas constroem para solucionar problemas que não podem ser dirigidos pelos mercados. Mercados e hierarquias são as instituições por excelência que as firmas utilizam para coordenar seus esforços em economias liberais de mercado. Em economias coordenadas de mercado, além de mercados e hierarquias, as firmas utilizam um conjunto adicional de organizações e instituições como apoio na coordenação de seus esforços.

Considerando que as firmas, em economias coordenadas de mercado, adotam modos de coordenação utilizando-se da interação estratégica, as instituições relevantes são aquelas que permitem um equilíbrio quanto às estratégias que possam oferecer retornos mais altos para todos os interessados. Geralmente, essas instituições são aquelas capazes de reduzir as incertezas relativas ao comportamento e ao comprometimento dos atores em relacionamento. Tais instituições assumem o papel de fornecer capacidades para a troca de informações entre os atores, para a monitoração do comportamento e para o estabelecimento de sanções para a falta de comportamento cooperativo. Essas instituições incluem associações comerciais ou patronais poderosas, sindicatos fortes, redes extensivas e cruzadas de acionistas, sistemas legais ou regulatórios para facilitar o compartilhamento de informações e colaboração, incluindo ainda instituições deliberativas para encorajar os agentes relevantes na realização de discussões coletivas para o alcance de acordo recíproco.

\section{O papel das regras informais, da cultura e da história}

A presença de um conjunto formal de instituições é freqüentemente uma precondição para que um equilíbrio possa ser atingido em contextos de coordenação. Não obstante, a presença de instituições formais raramente é suficiente para garantir esse equilíbrio. Em muitos casos, o que garante esse equilíbrio entre os atores é um conjunto de entendimentos partilhados quanto ao que cada um faz no relacionamento, os quais freqüentemente estão arraigados em um sentido do que é apropriado fazer em determinadas circunstâncias. Portanto, regras informais e entendimentos partilhados são considerados elementos importantes do conhecimento comum que levam os participantes em interação a coordenar esforços para alcançar certos resultados, algo que em circunstâncias puramente formais não seria possível atingir (Hall e Soskice, 2001).

Esse conhecimento comum é considerado o ponto de entrada na análise da cultura e da história. Os entendimentos partilhados ao longo da experiência de interação entre um conjunto familiar de atores ou as estratégias para ação que eles desenvolveram da experiência de operar em um determinado ambiente definem o conceito de cultura. Esse conceito não se baseia apenas em premissas sociológicas, mas em 
FÓRUM - A TEORIA INSTITUCIONAL EM UM CONTEXTO BRASILEIRO: DINÂMICAS DE INOVAÇ̃̃O E

IMITAÇÃO - O INSTITUCIONALISMO E A ABORDAGEM DAS INTERAÇÕES ESTRATÉGICAS DA FIRMA

Marcelo Bronzo - Luiz Honório

questões econômicas relacionadas aos problemas de contratação incompleta, enfrentados pelas organizações.

A perspectiva defendida por Hall e Soskice (2001) converge com as idéias sustentadas por Meyer e Rowan (1992). Para esses autores, estruturas organizacionais formais mantêm uma relação direta com o ambiente institucional e são refletidas na forma de mitos. Profissões, produtos, serviços, técnicas, políticas e programas institucionalizados funcionam como mitos, fazendo com que a organização, cerimonialmente, os adote e os incorpore a novas práticas e procedimentos. As organizações e seus conceitos racionalizados dominantes de organização do trabalho estabelecem uma conformidade com estruturas institucionais racionalizadas (mitos), os quais, por sua vez, tornam as organizacionais formais mais comuns e mais facilmente gerenciadas.

O argumento de Meyer e Rowan (1992) apresenta implicações teóricas importantes: (i) domínios ambientais que possuem um número maior de mitos racionais institucionalizados geram organizações mais formais; (ii) organizações que incorporam mitos institucionalizados são mais bem legitimadas, bem sucedidas e possuem maior probabilidade de sobrevivência; (iii) esforços para o controle organizacional, especialmente em contextos altamente institucionalizados, podem ser entendidos como direcionadores para a conformidade ritual, tanto interna quando externa à organização.

Seguindo a mesma linha de raciocínio, Zucker (1987) argumenta que boa parte do arcabouço teórico do institucionalismo ressalta o fato de que as organizações são influenciadas por pressões normativas que podem se originar tanto de fontes externas, como o Estado, quanto de fontes internas à própria organização. Significa dizer que tais pressões fazem com que a organização seja guiada por valores legitimados institucionalmente. A adoção de tais elementos, legitimados em conformidade com o ambiente institucional, aumenta a probabilidade de sobrevivência da organização.

Zucker (1987) observa que a implementação de elementos institucionais em uma organização implica um paradoxo. Ao mesmo tempo em que tais elementos legitimam rotinas existentes, resultando em estabilidade, eles criam elementos novos que se tornam institucionais com o tempo. Três princípios definem os elementos institucionais, sob essa perspectiva: (i) eles surgem principalmente de pequenos grupos ou de processos organizacionais; (ii) processo e estrutura organizacionais formalizados tendem a ser altamente institucionalizados e fontes de nova institucionalização e (iii) a institucionalização aumenta a estabilidade, criando rotinas que aumentam o desempenho organizacional (exceto quando alternativas mais eficientes são, por algum motivo, ignoradas).

Em uma perspectiva mais abrangente de análise, Hall e Soskice (2001) propõem que o desenvolvimento histórico está relacionado ao desenvolvimento das instituições nos níveis internacional, nacional, regional e local. Por um lado, as instituições são criadas e formalizadas por ações legais, o mesmo acontecendo com os seus procedimentos de operação. Por outro lado, experiências históricas repetidas constroem um conjunto de expectativas comuns que permitem aos agentes econômicos estabelecerem, de alguma maneira, relações efetivas de coordenação. Significa dizer que as instituições centrais que sustentam a coordenação econômica não devem ser vistas como entidades criadas em algum ponto no tempo e que podem ser assumidas para operar efetivamente depois.

A viabilidade de permanência de tais instituições, incluindo-se aqui as próprias organizações, depende de como os entendimentos compartilhados pelos agentes econômicos são reafirmados periodicamente pela experiência histórica apropriada. Tal viabilidade depende também, conforme foi discutido ao 
FÓRUM - A TEORIA INSTITUCIONAL EM UM CONTEXTO BRASILEIRO: DINÂMICAS DE INOVAÇ̃̃O E

IMITAÇÃO - O INSTITUCIONALISMO E A ABORDAGEM DAS INTERAÇÕES ESTRATÉGICAS DA FIRMA Marcelo Bronzo - Luiz Honório

longo deste trabalho, da capacidade das empresas de combinar, proteger e utilizar estrategicamente os seus recursos internos, bem como da sua capacidade relacional. Essa capacidade relacional é crítica para a gestão dos recursos externos complementares, por meio da interação coordenada e estrategicamente orientada da empresa com outras firmas e demais instituições econômicas do seu campo interorga nizacional.

Não podem ser vistos como excludentes, portanto, os interesses das empresas em desenvolver competências internas e externas simultaneamente. Mais do que utilizar vínculos externos para compensar habilidades ou capacidades que as firmas não possuem internamente, muitos dos novos arranjos produtivos (influenciados pela necessidade de uma coordenação integrada dos fluxos de informação e recursos) catalisam exatamente o esforço sistemático das empresas em melhorar a sua capacidade relacional para, assim, expandir e tornar mais robustas suas próprias competências centrais.

Com o passar do tempo, o desenvolvimento de uma maior "densidade relacional" por parte das empresas traz consigo o potencial de garantir benefícios importantes, como a redução dos custos de transação, a otimização das suas estruturas de governança e a internalização de conhecimentos específicos dispersos em diferentes pontos da cadeia ampliada de valor da qual a empresa faz parte. Se tais premissas forem confirmadas, a capacidade relacional das organizações em uma determinada rede poderá ser tomada como um ativo estratégico e, portanto, como fonte potencial de vantagens competitivas sobre as operações de outras empresas e cadeias de suprimentos concorrentes.

\section{CONCLUSÃO}

Neste artigo, entre outras questões debatidas, procurourse demonstrar que a coordenação das atividades econômicas vista como um processo de alocação de recursos (como quer a teoria dos custos de transação) observará a estrutura organizacional em rede como útil principalmente à minimização dos custos de transação. Já a coordenação das atividades econômicas entendida prioritariamente como um processo dinâmico de criação de recursos (como propõe a corrente evolucionista) ressalta a estrutura em rede como impulsionadora dos processos de aprendizagem e de inovação entre as empresas, em um contexto de especialização de capacidades e complementaridade de recursos. Uma e outra perspectiva facilitam a compreensão de que, ao se minimizarem os impactos da concorrência e ao se aumentar o potencial para a complementaridade, a especialização dos parceiros na rede reforça a coerência quanto à trajetória tecnológica das firmas e pode vir a garantir uma maior estabilidade dos vínculos de relacionamento ao longo do tempo.

Procurou-se demonstrar neste trabalho que as manobras competitivas de crescimento a partir da utilização estratégica de recursos externos complementares - como ocorre caracteristicamente no caso das estruturas em rede - envolvem novas formas de coordenação e de controle interorganizacional e revelam a importância dos mecanismos de regulação micro-institucionais para o desenvolvimento de empresas e de cadeias produtivas. Não é acaso o fato de muitos estudos desenvolvidos nos campos da teoria organizacional e da sociologia das organizações estarem exatamente enfatizando esse ponto, sugerindo a importância das instituições (por extensão, dos ambientes institucionais) na construção de vínculos de relacionamento mais colaborativos entre as empresas, com todos os benefícios daí resultantes, como o crescimento da renda e de oportunidades de trabalho nessas regiões.

Ao introduzir as discussões relativas a uma abordagem teórica integradora para o fenômeno das interações estratégicas da firma, buscou-se aqui exatamente delimitar o contorno de uma perspectiva 
FÓRUM - A TEORIA INSTITUCIONAL EM UM CONTEXTO BRASILEIRO: DINÂMICAS DE INOVAÇÃO E

IMITAÇÃO - O INSTITUCIONALISMO E A ABORDAGEM DAS INTERAÇÕES ESTRATÉGICAS DA FIRMA

Marcelo Bronzo - Luiz Honório

para a aplicação de conceitos econômicos e organizacionais direta ou indiretamente relacionados à teoria institucionalista. Defendeurse, neste artigo, a perspectiva integradora subjacente à abordagem de Hall e Soskice (2001), que permite validar a compreensão de que as decisões de curto e longo prazos das empresas em relação às novas arquiteturas e formas de governança estão diretamente associadas à infra-estrutura institucional que contorna e suporta as dinâmicas de relacionamento entre os agentes econômicos em um mesmo campo interorganizacional, aos aspectos históricos e culturais de uma região ou população de organizações, bem como à capacidade relacional da firma ao longo do tempo.

A abordagem das interações es tratégicas da firma, portanto, além de representar um constructo teórico fundamentalmente integrador, favorece o aprofundamento dos debates nos círculos acadêmico e empresarial em relação ao conceito da estratégia corporativa, oferecendo uma visão mais ampla e interdisciplinar a respeito do comportamento das firmas e de outras instituições econômicas no capitalismo contemporâneo.

\section{REFERÊNCIAS BIBLIOGRÁFICAS}

BARLEY, S. R.; FREEMAN, J.; HYBELS, R. C. Strategic alliances in commercial biotechnology. In: NOHRIA, N.; ECCLES, R. G (orgs.) Networks and organizations: structure, form and action. Boston: Harvard Business School Press, p. 311-347, 1992.

BARNEY, J. B. How a firm's capabilities affect boundary decisions. Sloan Management Review, p. 137-145, Spring, 1999.

BARNEY, J. B.; HANSEN, M. H. Trustworthiness as a source of competitive advantage. Strategic Management Journal, Winter Special Issue, v. 15, p. 175-190, 1994.

COASE, R. H. The nature of the firm. Economica, v. 4, p. 386-405, 1937.

COOKE, P.; MORGAN, K. The associational economy: firms, regions and innovation New York: Oxford University Press, 1998.

CROUCH, C.; STREECK, W. Political economy of modern capitalism: mapping convergence and diversity. London: Sage, 1997.

DI MAGGIO, P.; POWELL, W. The iron cage revisited: institutional isomorphism and collective rationality in organizational fields. American Sociological Review, n. 48, p. 147-160, 1983.

DUBOIS, A.; HAKANSSON, H. Relationships as activity links. In: EBERS, M (org.) The formation of inter-organizational networks. New York: Oxford University Press, p. 43-65, 1997.

DYER, J.; OUCHI, W. Japanese style partnerships: giving companies a competitive edge. Sloan Management Review, v. 35, p. 51-63, Fall, 1993.

EBERS, M. Explaining inter-organizational network formation. In: EBERS, M (org.) The formation of inter-organizational networks. New York: Oxford University Press, p. 1-40, 1997. 
FÓRUM - A TEORIA INSTITUCIONAL EM UM CONTEXTO BRASILEIRO: DINÂMICAS DE INOVAÇÃO E IMITAÇÃO - O INSTITUCIONALISMO E A ABORDAGEM DAS INTERAÇÕES ESTRATÉGICAS DA FIRMA Marcelo Bronzo - Luiz Honório

FREEMAN, J.; BOEKER, W. The ecological analysis of business strategy. California Management Review, v. 26, n. 3, Spring, p. 73-85, 1984.

HALL, P. A.; SOSKICE, D. An introduction to varieties of capitalism. In: HALL, P. A.; SOSKICE, D. (eds.) Varieties of capitalism: the institutional foundations of comparative advantage. New York: Oxford University Press, p. 1-68, 2001.

HOLLINGSWORTH, J. R.; BOYER, R. Contemporary capitalism: the embeddedness of institutions. Cambridge: Cambridge University Press, 1997.

KOGUT, B. Joint Ventures and the option to expand and acquire. Management Science, v. 37, p. 1933, 1991.

LIPPARINI, A. Le competenze organizzative. Roma: Carocci editore, 1998.

LORENZONI, G.; LIPPARINI, A. The leveraging of interfirm relationships as a distinctive organizational capability: a longitudinal study. Strategic Management Journal, n. 20, p. 317-338, 1999.

MEYER, J. W.; ROWAN, B. Institutionalized organizations: formal structure as myth and ceremony. In: MEYER, J. W.; SCOTT, W. R. (orgs.) Organizational environments: ritual and rationality. London: Sage Publications, 1992.

NELSON, R.; WINTER, S. An evolutionary theory of economic change. Cambridge: Belknap Press, 1982.

NOHRIA, N. Is a network perspective a useful way of studying organizations? In: NOHRIA, N.; ECCLES, R. G. (orgs.) Networks and organizations: structure, form and action. Boston: Harvard Business School Press, p. 1-22, 1992.

NORTH, D. Institutions, institutional change and economic performance. New York: Cambridge University Press, 1990.

PENROSE, E. T. The theory of the growth of the firm. New York: John Wiley \& Sons, 1959.

PERROW, C. Small-firm networks. In: NOHRIA, N.; ECCLES, R. G. (orgs.) Networks and organizations: structure, form and action. Boston: Harvard Business School Press, p. 445-470, 1992.

PIORE, M. J. Fragments of a cognitive theory of technological change and organizational structure. In: NOHRIA, N.; ECCLES, R. G. (orgs.) Networks and organizations: structure, form and action. Boston: Harvard Business School Press, p. 430-444, 1992.

PIORE, M. J.; SABEL, C. F. The second industrial divide: possibilities for prosperity. Boston: Basic Books, 1984.

PORTER, M. E. Clusters and the new economics of competition. Harvard Business Review, p. 77-90, November-December, 1998.

PRAHALAD, C. K.; HAMEL, G. The core competence of the corporation. Harvard Business Review, v. 68, n. 3, p. 79-91, May, 1990. 
FÓRUM - A TEORIA INSTITUCIONAL EM UM CONTEXTO BRASILEIRO: DINÂMICAS DE INOVAÇÃO E IMITAÇÃO - O INSTITUCIONALISMO E A ABORDAGEM DAS INTERAÇÕES ESTRATÉGICAS DA FIRMA Marcelo Bronzo - Luiz Honório

RICHARDSON, G. B. The organization of industry. In: BUCKLEY, P. J.; MICHIE, J. (orgs.) Firms, organizations and contracts: a reader in industrial organization. New York: Oxford University Press, p. 59-74, 1996.

RING, P. S. Processes facilitating reliance on trust in inter-organizational networks. In: EBERS, M (org.) The formation of inter-organizational networks. New York: Oxford University Press, p. 113-145, 1997.

SCHUMPETER, J. A. A teoria do desenvolvimento econômico. São Paulo: Editora Nova Cultural, 1969. (original de 1911).

SOBRERO, M. Innovazione tecnologica e relazioni tra imprese: teoria e prassi Itália: Nuova Italia Scientifica, 1996.

TEECE, D. J.; PISANO, G.; SHUEN, A. Dynamic capabilities and strategic management. Strategic Management Journal, v. 18, n. 7, p. 509-533, 1997.

ZUCKER, L. G. Institutional theories of organization. Annual Review of Sociology, v. 13, p. 444-464, 1987.

WHITLEY, R. Divergent capitalisms: the social structuring and change of business systems. Oxford: Oxford University Press, 1999.

WILLIAMSON, O. E. Markets and hierarchies: analysis and antitrust implications. New York: The Free Press, 1975.

WILLIAMSON, O. E. The economic institutions of capitalism. New York: The Free Press, 1985.

\section{Artigo recebido em 14.02.2003. Aprovado em 16.06.2004.}

\section{Marcelo Bronzo}

Professor Adjunto do CEPEAD/CAD/UFMG. Doutor em Administração pelo Cepead-UFMG.

Interesses de pesquisa nas áreas de gerenciamento das cadeias de suprimento, relacionamentos colaborativos em atividades de produção e inovação.

E-mail: marcelobronzo@ cepead.face.ufmg.br

Endereço: Rua Curitiba 832, sala 1.009, Centro, Belo Horizonte - MG, 30170-120.

\section{Luiz Honório}

Professor e Doutorando pelo CEPEAD/FACE/UFMG.

Interesses de pesquisa nas áreas de internacionalização de empresas, redes interorganizacionais e gerenciamento das cadeias de suprimento.

E-mail: lucahonorio@cepead.face.ufmg.br

Endereço: Rua Ramalhete 115, apto 204. Anchieta - Belo Horizonte - MG, 30310-310 